\title{
Business intelligence system adoption, utilization and success - A systematic literature review
}

\author{
Noor UL-Ain \\ Università Ca' Foscari, \\ Venezia, Italy \\ noor.ulain@unive.it
}

\author{
Vaia Giovanni \\ Università Ca' Foscari, \\ Venezia, Italy \\ g.vaia@unive.it
}

\author{
William DeLone \\ American University, \\ Washington, DC., USA \\ wdelone@american.edu
}

\begin{abstract}
In recent era of technological advances and hyper-competition, Business intelligence (BI) systems have attracted significant attention from executives and decision makers, due to their ability to provide complex and competitive information inputs to the decision process. Research into the adoption, utilization, and success of BI systems has grown substantially over the past two decades. Evidence from the existing literature suggests that organizations have largely failed to capture the full benefits of BI systems. This study uses a systematic literature review to present comprehensive knowledge about what has been examined in the domain of BI system adoption, utilization, and success. The study reports that although user underutilization and resistance are key challenges, little empirical research has focused on user-centered issues.
\end{abstract}

\section{Introduction}

The advances in organizational information systems and technologies have led to the emergence of business intelligence systems in the late 1990s [13, 57]. A Business Intelligence (BI) system, commonly known as a suite of technological solutions [12], facilitates organizations to amass, integrate and analyze vast amounts of data to understand their opportunities, strengths and weaknesses [28].

BI systems differ from other information systems (e.g. DSS, TPS, EIS and ES ${ }^{1}$ ) by; i) facilitating more aggregation, systematic integration, and management of unstructured and structured data, ii) dealing with

\footnotetext{
${ }^{1}$ DSS (Decision support system), TPS (Transaction Processing system), EIS (Executive information system), and ES (Expert systems).
}

huge amount of data (e.g. "Big Data"), iii) providing increased processing capabilities to end users to discover new knowledge [55], and iv) offering analysis solutions, ad hoc query, reporting and forecasting [26, 61].

With an increased competition from both online and traditional businesses, these technological solutions have become extremely important for organizations to improve managerial practices and performance, as well as their product and services $[20,52]$. The BI market has increased worldwide about $7.3 \%$ in 2017 , with revenues up to $\$ 18.3$ billion, and it is expected to reach $\$ 22.8$ billion by the end of 2020 [25].

However, despite of the growing investments and great market expansion, evidence suggests that several organizations fail to reap benefits from the implemented BI systems [4]. In fact, nearly $70 \%$ to $80 \%$ BI projects fail to yield the expected returns [24], or often results in little or no benefits for organizations [59].

Scholars and practitioners are still debating strategic and tactical approaches to the successful adoption and use of BI systems, producing hundreds of publications on different media. But a limited number of studies have attempted to synthesize this existing body of knowledge. For instance, Jourdan, Rainer [31] summarized BI studies from 1997 to 2006 with a focus on the research strategies used such as theory/literature review, field study, survey, lab or field experiments etc. Similarly, Fitriana, Eriyatno [21] reviewed progress on BI studies from 2000 to 2011. They discussed the most popular research approaches - single approach and integrated approach - used within BI studies. Trieu [52] analysed BI studies from 2000 to 2015 to understand the processes through which organizations can attain value from BI systems. At the same time, an extensive stream of research has been completed in the past two decades to understand the BI system adoption, utilization and success (hereafter referred 
as AUS) at organizational and individual level [1, 2, $15,23]$.

No studies exist that summarize research findings related to the adoption, utilization and success of BI system. Through this systematic literature review on BI system adoption, utilization and success, we aim to: (i) comprehensively report on research methodologies, theoretical lenses, key areas of investigation and prior challenges, (ii) and provide knowledge gaps that need further investigation and suggest opportunities for future research.

To achieve these research objectives, the following questions have guided the analysis:

RQ1: What are the main areas of investigations and perspectives addressed in BI system adoption, utilization and success studies?

RQ2: What are the key theoretical lenses, adopted by studies regarding BI system AUS?

RQ3: What key challenges are faced by organizations regarding BI system AUS?

RQ4: What are the knowledge gaps within the current BI system AUS research?

This paper applies a systematic literature review (SLR) in order to analyze and synthesize the existing research studies related to BI system AUS [35]. The following sections include i) a description of the systematic literature review methodology, ii) descriptive findings, iii) the principal findings related to the research questions, iv) identified knowledge gaps, v) study limitations, vi) implications for theory and practice, and vii) conclusions.

\section{Methodology}

Initially, a comprehensive review protocol was developed to guide this systematic literature review. The aim of the review protocol is to minimize the likelihood of bias in the study [33]. The protocol provides a detailed plan for the systematic review, by specifying the approaches to be followed and quality measures or conditions to apply while selecting the literature [9]. It involves the following stages: identification of research, research questions, search procedure, the criteria for study selection, data extraction process and data synthesis [34].

Inclusion/exclusion criteria were applied to ensure that studies are relevant and within the boundaries of research objectives [22]. The inclusion criteria were applied to full-length peer reviewed studies and conference papers related to the BI system AUS research, as depicted in following Table 1. Furthermore, studies not available in full-length, book chapters, discussion notes, editorials and reports, highly technical articles, and duplicated studies were excluded from the review list (Table 1).

Table 1. Study inclusion/exclusion criteria

Inclusion Criteria

Studies published between the period of 2000-2017

Studied within the domain of BI system AUS research

Full-length peer reviewed studies

Published in English language

Available in selected

electronic databases

To explore the relevant material for review, the search was conducted using both an automated and manual search [21]. First, the automated search was primarily based on search terms or keywords and was performed as an electronic search using electronic databases [41]. To do so, ten leading databases were located through Google Scholar, encompassing journals in the field of information systems, management information system, operations management, business, management, social science interdisciplinary and information science (Table 2). The selected databases were deemed to be highly relevant, providing a comprehensive census of the literature for business intelligence field.

The search terms of interest were searched through the identified electronic databases to identify the relevant literature. The selected search terms included business intelligence system, data warehouse, online analytical processing (OLAP), dashboards, adoption, use and success. Apart from simple search strings, Boolean operators AND/OR were also applied to collect as many outcomes as possible. The year 2000 was chosen as the initial year because first few academic articles related to BI were found published in that year $[36,44]$.

\section{Table 2. Search procedure}

\begin{tabular}{l|l} 
Years & \multicolumn{1}{|c}{ 2000-2017 } \\
terms & $\begin{array}{l}\text { Business intelligence", "Business intelligence } \\
\text { system", "Antecedents of business intelligence }\end{array}$ \\
& system success", "Business intelligence system \\
& success, BI system acceptance, intelligence system \\
adoption, intelligence system use", "Data & warehouse "adoption" and/or "use", "OLAP \\
& "adoption" and/or "use", Business intelligence \\
& system" and/or "success" and/or "adoption" and/or \\
& "acceptance" and/or "use" \\
& MIS Quarterly \\
Journals & MISQ Executive \\
& Decision Support Systems \\
Journal of Management Information Systems \\
European Journal of Information Systems \\
Journal of Information Systems \\
Information \& Management \\
Communications of ACM \\
Information Systems Management \\
Journal of Management Information Systems
\end{tabular}




\begin{tabular}{|l|l}
\hline & Expert systems with Applications \\
& Behaviour \& Information Technology \\
& Computers in Human behavior \\
& Journal of strategic Information systems \\
& Behaviour \& Information Technology \\
& Information development \\
& Telematics and Informatics \\
& Highly relevant articles from other Journals \\
\hline Databases & $\begin{array}{l}\text { Emerald insight, ScienceDirect, EBSCOhost, } \\
\text { ProQuest, Wiley Online library, IEEE Xplore, } \\
\text { JSTOR Archive, Taylor \& Francis Online, Sage } \\
\text { Journals, Springer-Link, Web of Science }\end{array}$ \\
\hline
\end{tabular}

Additionally, a manual search was performed by adopting backward and forward approach [41] to ensure the completion of systematic search. In former approach, citations of identified articles were reviewed to trace additional references, and in the later approach, collected references were further used to identify relevant articles. Along with the empirical studies that have a key focus on BI system AUS, this review also takes an account of conceptual research that contribute to BI system AUS literature.

Upon completion of search process, the study identified 586 articles as potentially relevant to business intelligence domain.

The inclusion/exclusion criteria were applied to these results in order to find relevant studies. Initially, the title and abstract of each article were scanned. Despite having search terms appearing in the titles or abstracts, some studies were not conducted in BI system context and thus found irrelevant for this review. As a result, in the first step, 399 articles were excluded. This reduced the number of studies to 187 , which were then further filtered by skimming the full content of the article to ensure relevance. This resulted in 86 additional irrelevant articles, then eliminated from the review list, leaving 101 articles relevant to this study's subject (Figure 1).

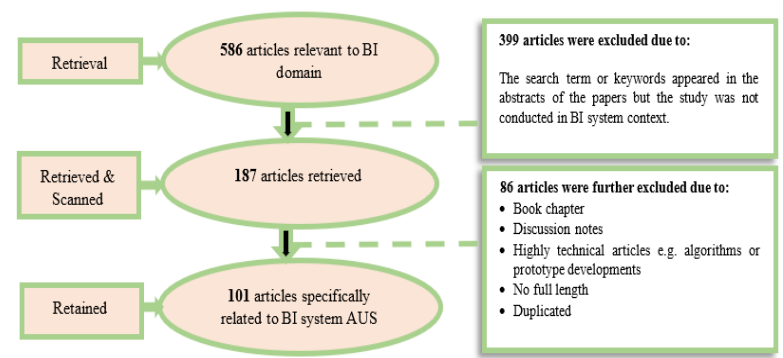

Figure 1. Articles selection and retention process

After selection of studies, the next step was to extract and code the information. The data from 101 articles were extracted as exemplified in Table 3.
Table 3. Data Extraction Form

\begin{tabular}{|c|c|c|c|c|c|c|}
\hline ID & Author & AOS & Topics & Tool & Sample & DCM \\
\hline B1 & $\begin{array}{c}\text { (Soliman, } \\
2000)\end{array}$ & $\begin{array}{l}\text { User satis } \\
\text { faction with } \\
\text { DW }\end{array}$ & Adoption & DW & $\begin{array}{c}42 \\
\text { managers }\end{array}$ & Survey \\
\hline B2 & $\begin{array}{c}\text { (Wixom \& } \\
\text { Watson, 2001) }\end{array}$ & DW success & Success & DW & $\begin{array}{c}225 \\
\text { employees }\end{array}$ & Survey \\
\hline $\begin{array}{c}\text { (Hart \& Porter, } \\
\text { 2004) }\end{array}$ & $\begin{array}{l}\text { Perceived } \\
\text { usefulness } \\
\text { of OLAP }\end{array}$ & Use & OLAP & $\begin{array}{c}56 \\
\text { respondents }\end{array}$ & $\begin{array}{c}\text { Mixed } \\
\text { Methods }\end{array}$ \\
\hline \multicolumn{2}{|l|}{ Note: AOS= Aim of study, DW = Data warehouse, DC= Data collection method } \\
\hline
\end{tabular}

\section{Descriptive analysis}

We define adoption, utilization and success concepts, as follows (Table 4):

\section{Table 4: Research topic categorization}

$$
\text { Topic }
$$

categorization

Adoption

Description

\begin{tabular}{|l|l|}
\hline Adoption & $\begin{array}{l}\text { Definition: The initial BI system usage [20, 40] } \\
\text { Description: Studies explaining the adoption, initial } \\
\text { BI system usage, users' intention and satisfaction, } \\
\text { and system evaluation }\end{array}$ \\
\hline Definition: The intensity of BI system use [18, 27] \\
Description: Studies explaining the extent of BI \\
system use, and its validation
\end{tabular}

The research on BI system AUS has increased significantly over last two decades. Figure 2 represents the distribution of all studies from the period of 2000 to 2017. There were only a few publications in the years between 2000 to 2010 .

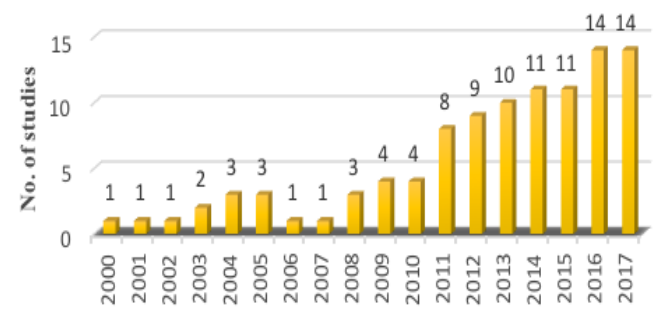

Figure 2. Publications by year from 20002017

From 2011 to 2017, there has been a significant increase in the number of studies; a total of 77 publications were published during this period. Further analysis revealed a change in the research focus from BI system components to overall BI system over the period of 2000-2017. In the earlier years, the research primarily focused on either data warehouses, or online analytical processing (OLAP), or both as shown in Table 5 . 
Table 5. BI system/BI tools adoption since 2000-2017

\begin{tabular}{|c|c|c|c|c|c|c|}
\hline \multirow[t]{2}{*}{ Years } & \multicolumn{6}{|c|}{ System/tool studies } \\
\hline & $\begin{array}{c}\text { Data } \\
\text { Warehouse }\end{array}$ & OLAP & Combined & $\begin{array}{l}\text { Dash- } \\
\text { boards }\end{array}$ & $\begin{array}{c}\text { BI } \\
\text { system }\end{array}$ & Total \\
\hline $\begin{array}{l}2000- \\
2004\end{array}$ & 6 & 1 & 2 & 0 & 1 & 10 \\
\hline $\begin{array}{l}2005- \\
2008\end{array}$ & 3 & 2 & 0 & 0 & 3 & 8 \\
\hline $\begin{array}{l}2009- \\
2012\end{array}$ & 1 & 0 & 0 & 0 & 22 & 23 \\
\hline $\begin{array}{l}2013- \\
2015\end{array}$ & 2 & 0 & 0 & 0 & 30 & 32 \\
\hline $\begin{array}{l}2015- \\
2017\end{array}$ & 1 & 0 & 0 & 1 & 26 & 28 \\
\hline Total & 13 & 3 & 2 & 1 & 82 & 101 \\
\hline
\end{tabular}

\section{Findings}

\subsection{Areas of investigations and perspectives}

The review of 101 studies represented three main areas of investigations i.e. adoption, utilization or success of BI system. The studies that mainly focused on how BI systems are being adopted by end-users, were analyzed to identify the factors that impact the adoption of BI systems in organizations. For instance, Zhao, Navarrete [47] identified how organization (industry, size resources), provider (vendor recognition, administration and deployment), project (team size, cost) and system (code, data and documentation quality) related factors are critical to the adoption of open source BI tools. Mathew [25] investigated the factors associated with BI system adoption namely task characteristics (decision support and task complexity), retailer category (management and size), BI system provider characteristics (access and affordability), and decision maker characteristics (technology, familiarity and quantitative skills).

Studies focused on BI system use discussed users' usage behavior towards BI systems, and the motivating factors that encourage users to use or continue using these systems. For example, Grublješič and Jaklič [16] uncovered constructs such as governance, coverage of user requirements, influence of peers, influence of organization, perceived ease of use and usefulness, user support, trust as main drivers of BI system's continuous use.

Those studies that focused on how organizations achieve success through the use of BI systems mainly discussed the success factors and outcomes such as impacts, benefits and performances. Wieder, Ossimitz [43] identified factors such as BI management, data quality, BI scope, user satisfaction and BI use important for achieving benefits (decision quality and performance) from BI tools.
The selected studies were further analyzed to categorize main perspectives and lines of investigation. Taking into account the categorization method by Hwang, $\mathrm{Ku}$ [19], the analysis revealed three main categories (Table 6). The first category is the 'organizational perspective', which describes how the alignment of organizational goals, strategies, plans and priorities with the BI systems affect adoption, utilization or success. Within this category, scholars focused on factors such as management support [10], human resources, BI (change) management [42], technology driven strategy [3] etc. The second category, the 'IS perspective,' highlights IS related factors such as technological BI capabilities [24], information and system quality [26], and scalable and flexible IT infrastructure [16].

Table 6. Perspectives on $\mathrm{BI}$ - adoption, use \& success

\begin{tabular}{|c|c|c|c|c|}
\hline \multirow{2}{*}{ Perspectives } & \multirow{2}{*}{ Success Factors } & \multicolumn{3}{|c|}{$\begin{array}{l}\text { No. of studies per } \\
\text { category }\end{array}$} \\
\hline & & $\mathbf{A}$ & $\mathbf{U}$ & $\mathbf{S}$ \\
\hline \multirow{10}{*}{ 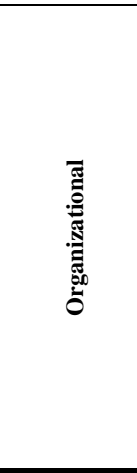 } & $\begin{array}{c}\text { Management } \\
\text { support }\end{array}$ & 2 & 3 & 6 \\
\hline & Human Resources & 7 & 6 & 9 \\
\hline & Culture & 2 & 1 & 2 \\
\hline & Social influence & 3 & 3 & \\
\hline & $\begin{array}{c}\text { Change } \\
\text { management }\end{array}$ & 3 & 4 & 3 \\
\hline & $\begin{array}{c}\text { Organization size } \\
\text { and capabilities }\end{array}$ & 4 & & \\
\hline & Service quality & & 1 & 3 \\
\hline & $\begin{array}{c}\begin{array}{c}\text { Strategy, vision } \\
\text { and goals }\end{array} \\
\end{array}$ & & 1 & 2 \\
\hline & $\begin{array}{c}\text { External } \\
\text { environment }\end{array}$ & 3 & 1 & \\
\hline & $\begin{array}{c}\text { Organizational } \\
\text { learning }\end{array}$ & 2 & & \\
\hline \multirow{9}{*}{ 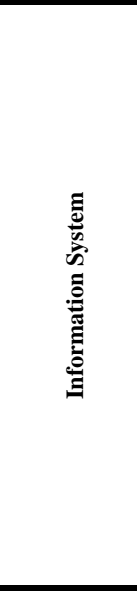 } & $\begin{array}{c}\text { Information/Data } \\
\text { Quality }\end{array}$ & 4 & 12 & 9 \\
\hline & System quality & 3 & 2 & 5 \\
\hline & $\begin{array}{c}\text { Perceived ease of } \\
\text { use }\end{array}$ & 3 & 3 & \\
\hline & $\begin{array}{c}\text { Perceived } \\
\text { Usefulness } \\
\end{array}$ & 4 & 3 & 1 \\
\hline & Job relevance & & 2 & \\
\hline & $\begin{array}{c}\text { Performance } \\
\text { expectancy, effort } \\
\text { expectancy }\end{array}$ & & 5 & \\
\hline & $\begin{array}{c}\text { IT infrastructure, } \\
\text { integration }\end{array}$ & & 1 & 3 \\
\hline & $\begin{array}{l}\text { Information and } \\
\text { analysis usage, } \\
\text { Technical } \\
\text { readiness of BI }\end{array}$ & 3 & 2 & 2 \\
\hline & $\begin{array}{c}\text { Data source, Data } \\
\text { type, Data } \\
\text { reliability }\end{array}$ & & & 1 \\
\hline \multirow{3}{*}{$\stackrel{\grave{D}}{\grave{D}}$} & $\begin{array}{c}\text { Absorptive } \\
\text { capacity }\end{array}$ & 1 & 1 & \\
\hline & $\begin{array}{c}\text { Team IT } \\
\text { knowledge and } \\
\text { technical skills }\end{array}$ & 2 & 2 & 1 \\
\hline & User Involvement & & & 1 \\
\hline
\end{tabular}




\begin{tabular}{|l|c|l|l|l|}
\hline & $\begin{array}{c}\text { Personal } \\
\text { innovativeness }\end{array}$ & 1 & & \\
\cline { 2 - 5 } & $\begin{array}{c}\text { Loss of power, } \\
\text { Changes in } \\
\text { decision-making }\end{array}$ & & 1 & \\
\cline { 2 - 5 } & $\begin{array}{c}\text { Conscientiousness } \\
\text { emotional } \\
\text { stability, } \\
\text { extraversion, } \\
\text { openness to } \\
\text { experience }\end{array}$ & & 3 & \\
\hline
\end{tabular}

The third category is the 'users' perspective', which considers of human related factors. The analysis of these factors reveals that human factors have been inadequately studied to evaluate BI system AUS. In summary, the focus of majority of BI system studies has been either on identifying organizational or IS related factors with different perspectives on adoption, utilization or success.

\subsection{Key theoretical lenses}

Analysis revealed that the 101 studies have employed a wide range of theories and models to examine BI system adoption, utilization or success. A total of 25 different theories, frameworks, or models have been applied to the BI system research (Table 7).

\section{Table 7. Theories used in BIS AUS research}

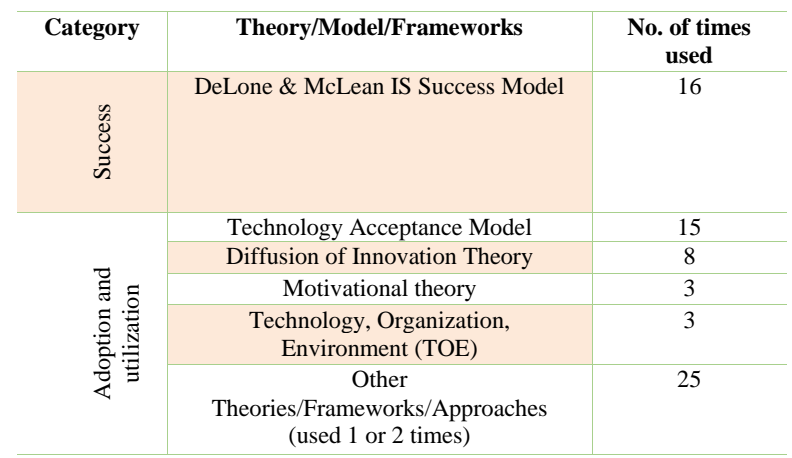

Among these theories/frameworks/models, the DeLone \& McLean's (D\&M) IS Success Model, the Technology Acceptance Model, and the Diffusion of Innovation Theory were found as the most commonly used models applied to BI system AUS studies.

The DeLone \& McLean's (D\&M) model $[12,13]$ is one of the most cited model to assess the information system success. The model proposed six success dimensions, namely; information quality, service quality, system quality, use, user satisfaction and net benefits $[12,13]$. These dimensions cover the whole spectra of information flows from the original production, through consumption, and to influence on organizational and individual performance. In the context of BI system research, the D\&M model has been the most influential framework in exploring the BI system success. A total of 16 studies adopted this framework to investigate critical factors to BI system success, and how BI system influence individual and organizational performance. For instance, a study conducted by Shin [35] found that users' satisfaction is dependent on system quality factors such as data locatability, data quality and system throughput. Mudzana and Maharaj [26] applied the IS success framework as a means of investigating how quality factors (including system quality, information quality, service quality) contribute to the success of BI system.

The second most adopted model in BI system AUS research, is Technology Acceptance Model (TAM), proposed by Davis [9]. TAM is considered as one of the most famous and parsimonious model for evaluating individuals' acceptance of IT. The model constitutes two key constructs: perceived usefulness (PU) and perceived ease of use (PEOU), which influence an individual's usage behavior. Five studies have applied TAM to investigate the perception of $\mathrm{BI}$ technology and the intention to accept or use BI technology [7, 23, 47]. For instance, Kohnke, Wolf [23] found PEOU as a strongest predictor of users' behavior intention in BI system context.

The next most cited framework is the Diffusion of Innovation (DOI theory), proposed by Rogers Everett [32]. According to DOI, innovation is communicated through different channels over time and within a particular social system [32]. The theory proposes five perceived characteristics of innovation adoption, namely: compatibility, complexity, observability, relative advantage, and trialability. The analysis revealed 8 studies in total that used DOI theory to explore BI technology adoption.

For instance, Yoon, Ghosh [46] and Boonsiritomachai, McGrath [6] applied DOI to investigate how relative advantage, compatibility, complexity and related factors impact BI technology adoption.

On the other hand, the adoption rate of other theories such as Technology-organizationenvironment (TOE) framework and Motivation theory were relatively low.

\subsection{Key challenges in BI system AUS}

BI systems are important for organizations because of their ability to predict and solve problems in a way that enhances organizational decision processes, enables effective actions, and helps to 
attain organizational goals [30]. However, this study found that there are many challenges faced by the organizations in terms of system adoption, usage and implementation success. Few challenges, highlighted in recent studies, have been listed in Table 8.

Based on the review, the greatest challenge faced when adopting BI systems is the "individual level acceptance and use". Low levels of acceptance or user resistance to use BI system are key challenges for management [8, 15, 23, 29]. Researchers highlighted users' lack of motivation, capabilities, ability to explore system and system logic, and system errors as key challenges at users' level [33, 43]. Similarly, Popovič [29] revealed fear of losing power over information, change in job skills (e.g. requirement of new skills to perform routine tasks), change in decision-making approach (e.g. integrating BI system into organizational processes) are the main reasons of users' resistance towards system.

Since BI system support analytical decisionmaking in knowledge-intensive activities, some challenges will most likely relate to lack of knowledge about system and absence of (required) technical skills [6]. Users may be unwilling to embed BI systems into their routine tasks, if they believe they do not possess the required knowledge and technical skills to use that system.

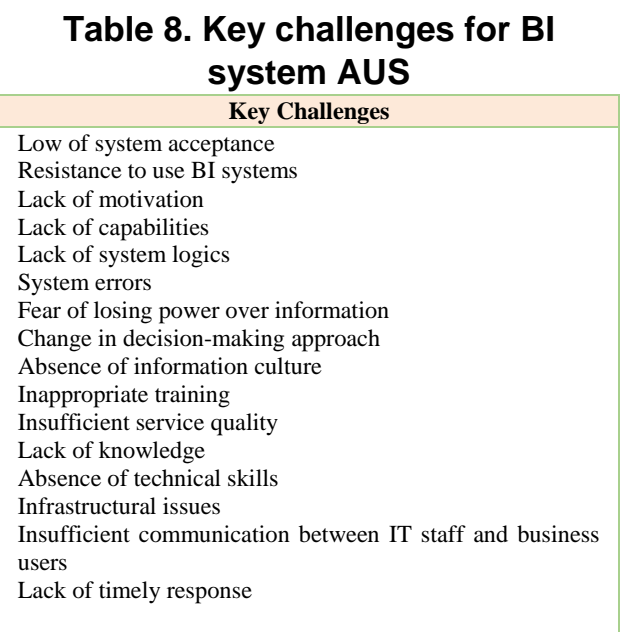

Other researchers have pointed out that the use and success of BI system are also affected by infrastructural issues [17, 28], such as insufficient communication between IT staff and business users on the use of system [31], absence of information culture, inappropriate training, insufficient service quality [29]. Deng and Chi [14] found that lack of timely response, related to user's difficulty in employing system features to their assigned tasks, could limit BI system use.

\section{Knowledge gaps and prospects for future research}

An examination of selected studies identifies that research on BI system adoption, utilization and success (AUS) has evolved gradually, and has prompted increased interest and attention among scholars and practitioners over the last decade. From the review's findings, it is notable that within existing body of knowledge organizational and IS perspectives were more frequently considered, while a little light has been shed on users' perspective (Table 6). The user's perspective with regards to BI system is important for understanding adoption, use and success of these systems.

The organization's goal of achieving high returns through BI system investments is highly dependent on the effective utilization of these systems [39]. Users' resistance or underutilization of BI system may result in work flow problems [29, 39] that subsequently results in strategy blindness [2] and negative business performance [14]. Therefore, it is important to understand individual level challenges, resolve them in order to exploit full benefits from the BI system and to reduce the risk of implementation failure [14, 29]. Future research should investigate user-centered approaches that can improve effective utilization of BI systems.

One promising focus for future research would be individual user IT competencies i.e. IT related skills, IT knowledge, utilization ability or any other related characteristics. Research on IT competencies is important as the use of BI system comprises reporting and analytics for end users. The former involves the creation of reports through drag and drop, whereas the latter involves business knowledge discovery and deep analysis with advance statistical functions [8]. With required IT competencies, users could more easily deploy BI system in their routine tasks, while the absence of competencies would require users to invest more effort in order to gain an understanding of BI functions and available data, which may lead them to avoid using system [34, 38, 45]. However, this review has revealed that no studies have empirically tested individual IT competencies in BI system AUS research contexts. Therefore, future BI system research should explore the impact of user IT competencies. Future studies could apply individual-level theories such as motivation theory [11] and social cognitive theory [4, 5] to determine individual behavior in BI system research domain.

Additionally, the users' positive perception of improved performance would increase the likelihood 
of BI system using [16] and ultimately of BI system success. These findings revealed that researchers have overlooked perceived system impact in BI system AUS studies. Thus, this study suggests that a BI perceived impact (e.g. task productivity, task innovation and management control) - proposed by Torkzadeh and Doll [37] - could be studied to better understand the users' perspective about the innovative and productive use of BI system.

\section{Limitations}

This systematic literature review has several limitations that are important to be noted. Firstly, the literature search was limited to three main categories i.e. adoption, utilization and success of BI systems. Therefore, the results of the review and related future research opportunities are limited to these categories.

Future research may broaden the research strategy to identify different insights and opportunities in BI system research domain. Secondly, the focus of the review was limited to BI system and its components such as data warehouse, OLAP and Dashboards. Future studies may consider data exploration techniques, e.g. data mining, to provide useful insights. Lastly, the review comprehensively examined the theoretical lenses that are most influential in the field, and also examined key issues related to adoption, utilization and success. However, review did not count on the relationships among measures, and the strength of the relationships in the proposed frameworks of selected studies. The future research can employ a meta-analysis to extend knowledge in the domain.

\section{Implications for Theory and Practice}

The systematic literature review has implications for both academic scholars and practitioners. For scholars, the systematic review provides a valuable summary to understand the current state of BI system AUS research. The BI system adoption, utilization or success research is still progressing, so this review can serve as a reference for scholars as it summarizes the key areas/perspectives of investigation, theoretical lenses, and key implementation challenges in the BI system AUS studies to date. Additionally, the review provides a picture of existing literature and highlights the research gaps where further exploration is needed in order to assist organizations to improve use and success of BI system.

Researchers may apply one of the three most frequently used research frameworks or theories (DeLone \& McLean IS Success Model, TAM or
DOI) as foundation for their BI system research. In addition, researchers may apply and integrate individual level theories to reflect a more comprehensive view of BI system AUS. Secondly, researchers should devote more attention to explore the impact of user-centered factors such as impact of IT competencies on BI system - AUS.

For practitioners such as business analysts, managers and IT executives, the analysis of BI system AUS literature provides some preliminary insights. Despite increasing investments in BI systems, a number of organizations are still unable to attain the desired success from these systems due to underutilization and ineffective use [1, 24]. Our analysis of past two decades of research on BI system AUS shows that low user acceptance or resistance is one of the key challenges influencing BI system use and success. The analysis revealed that management support, user training, defined vision and goals, BI \& business strategy alignment, data and system quality, IT infrastructure etc. overcoming these challenges to AUS. However, organizations need to pay more attention to user-centered issues to improve the success of their BI system investments. For instance, a corporate culture based on facts, knowledge and learning can help organizations to use information offered by BI systems. In addition, the success of BI system is dependent on users [41], so organizations may emphasize the development of specific capabilities (on users) to realize the system success but also the organizational success.

\section{Conclusions}

This study has provided a comprehensive and systematic review of BI system adoption, utilization and success (AUS) research over the period of last two decades. Following rigorous guideline, 101 peerreviewed studies were selected and analyzed. The results obtained from review indicated that BI research covering the three main categories adoption, utilization or success, has witnessed a significant progress in the last decade. Nevertheless, there are many gaps in our understanding of BI system success and success drivers.

Researchers identified different issues that were critical to BI system adoption, utilization, and success. A close examination revealed that majority of studies examined mostly organizational and/or information systems factors, whereas user centered issues have been understudied even though user resistance or under-utilization is reported as a key challenge to BI system AUS. 
Note: All 101 references analyzed for this literature review can be found on the following link (https://drive.google.com/file/d/18ZxYtn4hVA1cfHi v-a_OsanB84opodBx/view?usp=sharing)

\section{References}

[1] Arefin, M.S., M.R. Hoque, and Y. Bao, "The impact of business intelligence on organization's effectiveness: an empirical study", Journal of Systems and Information Technology, 2015, 17,3, pp. 263.

[2] Arnott, D., F. Lizama, and Y. Song, "Patterns of business intelligence systems use in organizations", Decision Support Systems, 2017, 97, pp. 58-68.

[3] Arvidsson, V., J. Holmström, and K. Lyytinen, "Information systems use as strategy practice: A multidimensional view of strategic information system implementation and use", The Journal of Strategic Information Systems, 2014, 23,1, pp. 45-61.

[4] Audzeyeva, A. and R. Hudson, "How to get the most from a business intelligence application during the post implementation phase? Deep structure transformation at a UK retail bank", European Journal of Information Systems, 2016, 25,1, pp. 29-46.

[5] Bach, M.P., A. Čeljo, and J. Zoroja, "Technology Acceptance Model for Business Intelligence Systems: Preliminary Research", Procedia Computer Science, 2016, 100, pp. 995-1001.

[6] Bandura, A., Self-efficacy: The exercise of control. 1997: Macmillan.

[7] Bandura, A., Social foundations of thought and action: A social cognitive theory. 1986: Englewood Cliffs, NJ, US: Prentice-Hall, Inc.

[8] Boonsiritomachai, W., G.M. McGrath, and S. Burgess, "Exploring business intelligence and its depth of maturity in Thai SMEs", Cogent Business \& Management, 2016, 3,1, pp. 1220663.

[9] Brereton, P., et al., "Lessons from applying the systematic literature review process within the software engineering domain", Journal of systems and software, 2007, 80,4, pp. 571-583.

[10] Brockmann, T., et al. "User acceptance of mobile business intelligence services", in Network-Based Information Systems (NBiS), 2012 15th International Conference on. 2012. IEEE.

[11] Chang, Y.-W., P.-Y. Hsu, and Z.-Y. Wu, "Exploring managers' intention to use business intelligence: the role of motivations", Behaviour \& Information Technology, 2015, 34,3, pp. 273-285.
[12] Chaudhuri, S., U. Dayal, and V. Narasayya, "An overview of business intelligence technology", Communications of the ACM, 2011, 54,8, pp. 88-98.

[13] Chen, H., R.H. Chiang, and V.C. Storey, "Business intelligence and analytics: from big data to big impact", MIS quarterly, 2012, pp. 1165-1188.

[14] Davis, F.D., "Perceived usefulness, perceived ease of use, and user acceptance of information technology", MIS quarterly, 1989, pp. 319-340.

[15] Dawson, L. and J.-P. Van Belle, "Critical success factors for business intelligence in the South African financial services sector", South African Journal of Information Management, 2013, 15,1, pp. 1-12.

[16] Deci, E.L. and R.M. Ryan, Handbook of selfdetermination research. 2002: University Rochester Press.

[17] Delone, W.H. and E.R. McLean, "The DeLone and McLean model of information systems success: a ten-year update", Journal of management information systems, 2003, 19,4, pp. 9-30.

[18] DeLone, W.H. and E.R. McLean, "Information systems success: The quest for the dependent variable", Information systems research, 1992, 3,1, pp. 60-95.

[19] Deng, X. and L. Chi, "Understanding postadoptive behaviors in information systems use: A longitudinal analysis of system use problems in the business intelligence context", Journal of Management Information Systems, 2012, 29,3, pp. 291-326.

[20] Elbashir, M.Z., et al., "Enhancing the business value of business intelligence: The role of shared knowledge and assimilation", Journal of Information Systems, 2013, 27,2, pp. 87-105.

[21] Fitriana, R., T.D. Eriyatno, and T. Djatna, "Progress in Business Intelligence System research: A literature Review", International Journal of Basic \& Applied Sciences IJBAS-IJENS, 2011, 11,03, pp. 118503-6464.

[22] Foshay, N., A. Taylor, and A. Mukherjee, "Winning the hearts and minds of business intelligence users: The role of metadata", Information Systems Management, 2014, 31,2, pp. 167-180.

[23] Gaardboe, R., T. Nyvang, and N. Sandalgaard, "Business intelligence success applied to healthcare information systems", Procedia Computer Science, 2017, 121, pp. 483-490.

[24] Gartner. "Business Intelligence \& Analytics Summit ", 2015; Available from: https://www.gartner.com/newsroom/id/3130017. 
[25] Gartner. "Business Intelligence and Analytics Trends ", 2017; Available from: https://www.gartner.com/newsroom/id/3612617.

[26] Grublješič, T. and J. Jaklič, "Conceptualization of the business intelligence extended use model", Journal of Computer Information Systems, 2015, 55,3, pp. 72-82.

[27] Hannula, M. and V. Pirttimaki, "Business intelligence empirical study on the top 50 Finnish companies", Journal of American Academy of Business, 2003, 2,2, pp. 593-599.

[28] Harrison, R., et al., "The role of technology in the management and exploitation of internal business intelligence", Journal of Systems and Information Technology, 2015, 17,3, pp. 247-262.

[29] Hou, C.-K. and K.N. Papamichail, "The impact of integrating enterprise resource planning systems with business intelligence systems on decision-making performance: an empirical study of the semiconductor industry", International journal of technology, policy and management, 2010, 10,3, pp. 201-226.

[30] Hwang, H.-G., et al., "Critical factors influencing the adoption of data warehouse technology: a study of the banking industry in Taiwan", Decision Support Systems, 2004, 37,1, pp. 1-21.

[31] Jourdan, Z., R.K. Rainer, and T.E. Marshall, "Business intelligence: an analysis of the literature", Information Systems Management, 2008, 25,2, pp. 121131.

[32] Karahanna, E., D.W. Straub, and N.L. Chervany, "Information technology adoption across time: a crosssectional comparison of pre-adoption and post-adoption beliefs", MIS quarterly, 1999, pp. 183-213.

[33] Kitchenham, B., "Procedures for performing systematic reviews", Keele, UK, Keele University, 2004, 33,2004, pp. 1-26.

[34] Kitchenham, B. and S. Charters, "Guidelines for performing Systematic Literature Reviews in Software Engineering.", 2007, V2, pp. 1-65.

[35] Kitchenham, B., et al., "Systematic literature reviews in software engineering-a tertiary study", Information and Software Technology, 2010, 52,8, pp. 792-805.

[36] Kohnke, O., T.R. Wolf, and K. Mueller, "Managing user acceptance: an empirical investigation in the context of business intelligence standard software", International Journal of Information Systems and Change Management, 2011, 5,4, pp. 269-290.

[37] Kokin, S. and T.N. Wang. "Business Intelligence: Relationship between Capabilities, Success and Decision Environment", in Applied Mechanics and Materials. 2014. Trans Tech Publ.
[38] Mathew, S.K., "Adoption of business intelligence systems in Indian fashion retail", International Journal of Business Information Systems, 2012, 9,3, pp. 261-277.

[39] Mudzana, T. and M. Maharaj, "Measuring the success of business-intelligence systems in South Africa: An empirical investigation applying the DeLone and McLean Model", South African Journal of Information Management, 2015, 17,1, pp. 1-7.

[40] Ngai, E.W., J. Poon, and Y.H. Chan, "Empirical examination of the adoption of WebCT using TAM", Computers \& education, 2007, 48,2, pp. 250-267.

[41] Olszak, C.M., "Toward better understanding and use of Business Intelligence in organizations", Information Systems Management, 2016, 33,2, pp. 105-123.

[42] Popovič, A., "If we implement it, will they come? User resistance in post-acceptance usage behaviour within a business intelligence systems context", Economic Research-Ekonomska Istraživanja, 2017, 30,1, pp. 911-921.

[43] Popovič, A., et al., "Towards business intelligence systems success: Effects of maturity and culture on analytical decision making", Decision Support Systems, 2012, 54,1, pp. 729-739.

[44] Richards, G., et al., "Business intelligence effectiveness and corporate performance management: An empirical analysis", Journal of Computer Information Systems, 2017, pp. 1-9.

[45] Rogers Everett, M., "Diffusion of innovations", New York, 1995, 12.

[46] Seah, M., M.H. Hsieh, and P.-D. Weng, "A case analysis of Savecom: The role of indigenous leadership in implementing a business intelligence system", International journal of information management, 2010, 30,4, pp. 368373.

[47] Shih, H.-P., "Assessing the effects of self-efficacy and competence on individual satisfaction with computer use: An IT student perspective", Computers in Human Behavior, 2006, 22,6, pp. 1012-1026.

[48] Shin, B., "An exploratory investigation of system success factors in data warehousing", Journal of he Association for Information Systems, 2003, 4,1, pp. 6.

[49] Soliman, K.S., E. Mao, and M.N. Frolick, "Measuring user satisfaction with data warehouses: an exploratory study", Information \& Management, 2000, 37,3, pp. 103110.

[50] Torkzadeh, G. and W.J. Doll, "The development of a tool for measuring the perceived impact of information technology on work", Omega, 1999, 27,3, pp. 327-339. 
[51] Torkzadeh, G. and J. Lee, "Measures of perceived end-user computing skills", Information \& Management, 2003, 40,7, pp. 607-615.

[52] Trieu, V.-H., "Getting value from Business Intelligence systems: A review and research agenda", Decision Support Systems, 2017, 93, pp. 111-124.

[53] Wang, H.-C., "Distinguishing the adoption of business intelligence systems from their implementation: the role of managers' personality profiles", Behaviour \& Information Technology, 2014, 33,10, pp. 1082-1092.

[54] Webster, J. and R.T. Watson, "Analyzing the past to prepare for the future: Writing a literature review", MIS quarterly, 2002, pp. xiii-xxiii.

[55] Wieder, B. and M.-L. Ossimitz, "The impact of Business Intelligence on the quality of decision making-a mediation model", Procedia Computer Science, 2015, 64, pp. 1163-1171.

[56] Wieder, B., M. Ossimitz, and P. Chamoni, "The impact of business intelligence tools on performance: a user satisfaction paradox?", 2012.

[57] Wixom, B. and H. Watson, "The BI-Based Organization", International Journal of Business Intelligence Research (IJBIR), 2010, 1,1, pp. 13-28.

[58] Wixom, B.H. and H.J. Watson, "An empirical investigation of the factors affecting data warehousing success", MIS quarterly, 2001, pp. 17-41.

[59] Yeoh, W. and A. Popovič, "Extending the understanding of critical success factors for implementing business intelligence systems", Journal of the Association for Information Science and Technology, 2016, 67,1, pp. 134-147.

[60] Yoon, C.Y., "A structural model of end-user computing competency and user performance", Knowledge-Based Systems, 2008, 21,5, pp. 415-420.

[61] Yoon, T.E., B. Ghosh, and B.-K. Jeong. "User acceptance of business intelligence (BI) application: Technology, individual difference, social influence, and situational constraints", in System Sciences (HICSS), 2014 47th Hawaii.

[62] Zhao, Z., C. Navarrete, and A. Iriberri, "Open source alternatives for business intelligence: Critical success factors for adoption", 2012. 